\title{
Endobronchial mimics of primary endobronchial carcinoma: A clinical study of 25 cases
}

\author{
Cynthia M Magro MD ${ }^{1}$, Patrick Ross Jr MD PhD²
}

\begin{abstract}
CM Magro, P Ross Jr. Endobronchial mimics of primary endobronchial carcinoma: A clinical study of 25 cases. Can Respir J 2005;12(3):123-127.

While endobronchial lesions that present with symptoms of obstruction may be reflective of primary bronchogenic malignancy, there have been a number of reports of bronchial lesions other than primary bronchogenic carcinoma simulating primary endobronchial epithelial malignancy clinically. Twenty-five cases of symptomatic endobronchial disease were encountered with pathological assessment demonstrating an endobronchial process other than carcinoma, representing metastatic disease (breast, colon, renal, head and neck origin), fungal infection, Hodgkin's lymphoma, primary bronchogenic melanoma, lipoma, broncholith and inflammatory pseudopolyp. The present report underscores the potential pathogenetic heterogeneity encountered in lesions presenting with signs and symptoms of endobronchial obstruction, emphasizing the critical role of biopsy for establishing a definitive diagnosis.
\end{abstract}

Key Words: Bronchus; Mimics of primary bronchogenic carcinoma; Tumour

E ndobronchial lesions comprise a heterogeneous group of

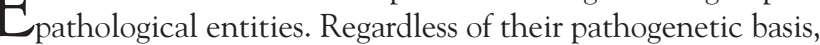
similar obstructive signs and symptoms develop; hemoptysis, cough and/or dyspnea are characteristic. The most frequent pathogenetic basis is primary bronchogenic malignancy including bronchogenic small cell carcinoma, well-differentiated neuroendocrine carcinomas, bronchogenic squamous cell carcinoma and nonsmall cell carcinoma (1). However, previous reports (2-6) have reported other etiologies, including infection, lymphoma, endobronchial hamartomatous lesions, other rare forms of primary endobronchial neoplasia and finally, metastatic disease. The purpose of the present study was to explore the spectrum of endobronchial lesions in which pathological examination established a diagnosis other than primary pulmonary carcinoma. Three of these patients have been previously reported $(3,5)$. The clinical features, including bronchoscopic assessment and pathological findings, are described.

\section{PATIENTS AND METHODS}

The patient database of one of the authors (PR), a cardiothoracic surgeon, revealed 23 cases in whom the clinical history and bronchoscopic assessment were suspicious for a primary endobronchial carcinoma but subsequent pathological assessment demonstrated an endobronchial process other than primary bronchogenic carcinoma. The cases were collected over a three-year time period, in which the

\section{Simulation de cancer endobronchique primitif : étude clinique de 25 cas}

\begin{abstract}
S'il est vrai que certaines lésions endobronchiques, qui se manifestent par des symptômes d'obstruction, peuvent être révélatrices d'un cancer bronchopulmonaire primitif, d'autres lésions bronchiques, différentes du cancer broncho-pulmonaire primitif, simulent, sur le plan clinique, une tumeur maligne primitive de l'épithélium endobronchique. À preuve : une étude de vingt-cinq cas de lésions endobronchiques symptomatiques dont l'examen pathologique faisait état de processus morbides évolutifs, différents du carcinome; parmi les affections en cause figuraient les métastases (cancer du sein, du côlon, du rein, de la tête et du cou), les infections fongiques, la maladie de Hodgkin, le mélanome bronchopulmonaire primitif, le lipome, la broncholithiase et les pseudopolypes inflammatoires. Le présent rapport fait ressortir l'hétérogénéité des affections possibles se manifestant par des signes et des symptômes d'obstruction endobronchique et, par le fait même, le rôle crucial de la biopsie pour poser un diagnostic formel.
\end{abstract}

\footnotetext{
${ }^{1}$ Department of Pathology; ${ }^{2}$ Division of Cardiothoracic Surgery, The Ohio State University, Columbus, Ohio, USA

Correspondence: Dr Cynthia M Magro, Department of Pathology, The Ohio State University, N305 Doan Hall, 410 West 10th Avenue, Columbus, Ohio 43210-1218, USA. Telephone 614-293-5292, fax 614-293-7634, e-mail magro-1@medctr.osu.edu
} 
TABLE 1

Endobronchial lesions that mimic primary endobronchial carcinoma

\begin{tabular}{|c|c|c|c|c|}
\hline Age & Sex & Presenting signs and symptoms & Pathological diagnosis & $\begin{array}{l}\text { Location of lesion on } \\
\text { bronchoscopy }\end{array}$ \\
\hline 32 & M & Hemoptysis & Endobronchial cryptococcoma & Left mainstem \\
\hline 82 & $\mathrm{~F}$ & Recurrent hemoptysis; lung mass; S/P PDT & Histoplasmosis & Right upper lobe \\
\hline 53 & $\mathrm{~F}$ & Hemostasis and pulmonary infiltrate & Histoplasmosis-associated granulomatous pneumonitis & Right lower lobe \\
\hline 29 & M & Coughing and hemoptysis & Histoplasmosis & Right middle and lower lobes \\
\hline 66 & $\mathrm{~F}$ & Aysmptomatic & Malbranchea & Left mainstem \\
\hline 77 & $\mathrm{~F}$ & Asymptomatic; discovered on x-ray & Large cell malignant neoplasm consistent with melanoma & Right bronchus intermedius \\
\hline 47 & M & Hemoptysis & Hodgkin's lymphoma/mediastinum & Right mainstem \\
\hline 44 & M & Dyspnea & Hodgkin's lymphoma/mediastinum & Right upper lobe \\
\hline 60 & M & Dyspnea & Hodgkin's lymphoma/mediastinum & Right mainstem \\
\hline 43 & M & COPD; right lung abscess & Endobronchial lipoma & Right mainstem \\
\hline 71 & $\mathrm{~F}$ & Foreign body aspiration with subsequent wheezing & Calcified amorphous material & Posterior left lower lobe \\
\hline 39 & $\mathrm{~F}$ & Chronic aspiration & Granulation tissue formation with chronic active inflammation & Trachea \\
\hline
\end{tabular}

COPD Chronic obstructive pulmonary disease; F Female; M Male; S/P PDT Status post photodynamic therapy

TABLE 2

Metastatic endobronchial disease

\begin{tabular}{|c|c|c|c|c|c|c|c|c|}
\hline Age & Sex & Indication & $\begin{array}{l}\text { Primary } \\
\text { malignancy }\end{array}$ & $\begin{array}{l}\text { Date primary } \\
\text { malignancy } \\
\text { diagnosed }\end{array}$ & $\begin{array}{l}\text { Location in } \\
\text { endobronchus }\end{array}$ & $\begin{array}{l}\text { Date of } \\
\text { endobronchial } \\
\text { presentation }\end{array}$ & $\begin{array}{l}\text { Metastases } \\
\text { to other organs }\end{array}$ & $\begin{array}{l}\text { Date other } \\
\text { metastases } \\
\text { diagnosed }\end{array}$ \\
\hline 69 & $\mathrm{M}$ & Hemoptysis & Colon & $04 / 98$ & Right mainstem & $11 / 22 / 02$ & Liver, lung & $04 / 98$ \\
\hline 42 & M & Hemoptysis & Kidney & $09 / 96$ & Right upper lobe & $08 / 28 / 02$ & $\begin{array}{l}\text { Lung, pleura, brain, lymph nodes, } \\
\text { stomach, bowel, spleen, pancreas, } \\
\text { vertebrae }\end{array}$ & $08 / 99$ \\
\hline 61 & $\mathrm{~F}$ & Obstr/recurr & Breast & 04/97, 01/99 & Right upper lobe & $04 / 15 / 02$ & Lung & $10 / 03 / 01$ \\
\hline 62 & $\mathrm{M}$ & Obstr/recurr & Colon & $02 / 01$ & Right mainstem & $09 / 30 / 02$ & Bilateral lungs, lymph node & $02 / 02$ \\
\hline 41 & M & Postob pneum & Larynx & $03 / 96$ & Bronchus intermedius & $02 / 21 / 00$ & None & NA \\
\hline 34 & $\mathrm{~F}$ & SOB/obstr & Breast & $06 / 97$ & $\begin{array}{l}\text { Bronchus intermedius, } \\
\text { left distal mainstem }\end{array}$ & $\begin{array}{r}1 / 26 / 00 \\
2 / 4 / 00\end{array}$ & $\begin{array}{l}\text { Bilateral lungs, pleura, recurrent } \\
\text { right breast, left breast }\end{array}$ & $09 / 99,10 / 99$ \\
\hline 46 & $\mathrm{~F}$ & SOB/obstr & Breast & 1993 & Endotrachea & $12 / 05 / 00$ & $\begin{array}{l}\text { Recurrent right breast, bilateral lungs, } \\
\text { mediastinal lymph node, } \\
\text { liver, pleura, brain }\end{array}$ & $\begin{array}{l}\text { 1998, 09/13/99, } \\
\text { 07/25/00, } \\
\text { 08/11/00, 01/05/01 }\end{array}$ \\
\hline 43 & $\mathrm{~F}$ & SOB/obstr & Colon & $09 / 94$ & Bronchus intermedius & $04 / 26 / 00$ & Liver, lung & 05/16/95, 5/17/95 \\
\hline 42 & $\mathrm{M}$ & SOB/obstr & Kidney & 1995 & Right mainstem & $06 / 19 / 00$ & Lung & $06 / 06 / 00$ \\
\hline 57 & M & Hemoptysis & Piriform sinus & s $12 / 20 / 01$ & Left upper lobe & $10 / 29 / 02$ & Lung & $05 / 15 / 03$ \\
\hline 77 & M & Hemoptysis & Colon & 06/01/95 & Left upper lobe & $03 / 31 / 03$ & Lung & 05/05/99* \\
\hline 77 & M & Hemoptysis & Kidney & 06/19/95 & Right upper lobe & $10 / 02 / 02$ & Adrenal gland and liver & $11 / 07 / 02$ \\
\hline 36 & $\mathrm{~F}$ & Hemoptysis & Breast & $06 / 21 / 95$ & Bronchus intermedius & 02/09/00 & None & NA \\
\hline
\end{tabular}

F Female; M Male; na Not available; obstr Obstruction; post-ob pneum Post-obstructive pneumonia; recurr Recurrent; SOB Shortness of breath

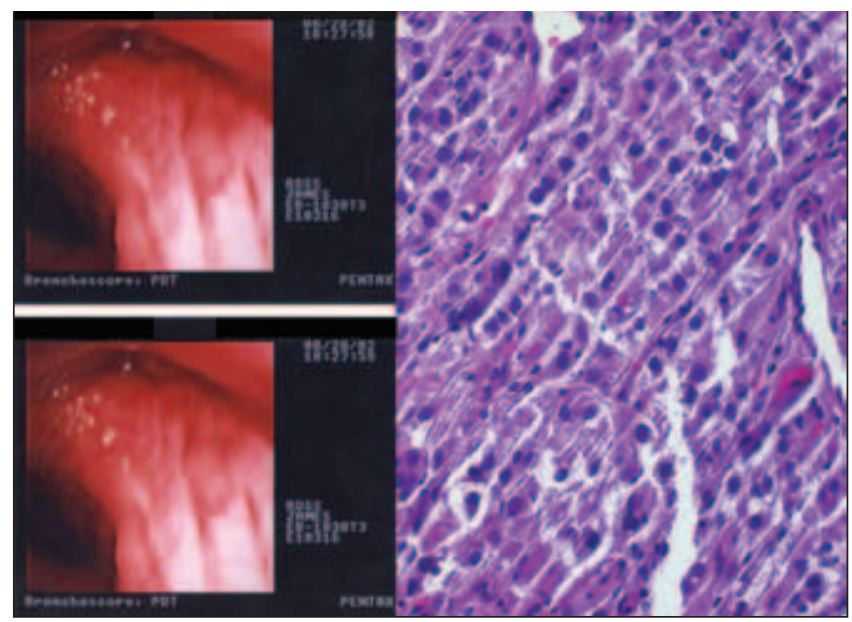

Figure 1) Metastatic group. There is a mass occluding the right upper lobe orifice and a rather striking neovascularity along the membranous portion of the left mainstem (left panel). Light microscopic examination was compatible with metastatic renal cell carcinoma (right panel) (patient 2 of the metastatic group) (Hematoxylin and eosin stain, original magnification $\times 200$ ) transcription factor-1 (primary lung carcinoma) and apoprotein-A1 (primary lung carcinoma), were used. Four of the patients who died were younger than 45 years of age and all had mainstem involvement. All patients had known primary tumours initially diagnosed and treated 19 months to eight years (mean 4.6 years) before their endobronchial presentation. Six of the 13 patients had metastatic disease involving other organs. In two of the cases, the metastatic lesions to the other sites occurred simultaneously with the endobronchial presentation, while in the remainder of the cases, it preceded the endobronchial presentation. Overall, the mean time that elapsed between the presentation at other metastatic sites and subsequent development of endobronchial metastatic disease was approximately 1.8 years. A single patient had metastatic disease confined to the bronchus. The site localization of the endobronchial tumour included the right upper lobe $(n=3)$, right mainstem $(n=3)$, bronchus intermedius $(n=4)$, left main stem $(n=1)$, left upper lobe $(n=2)$ and trachea $(n=1)$. All patients presented with symptoms of obstruction; seven received photodynamic therapy (PDT) with successful palliation. 


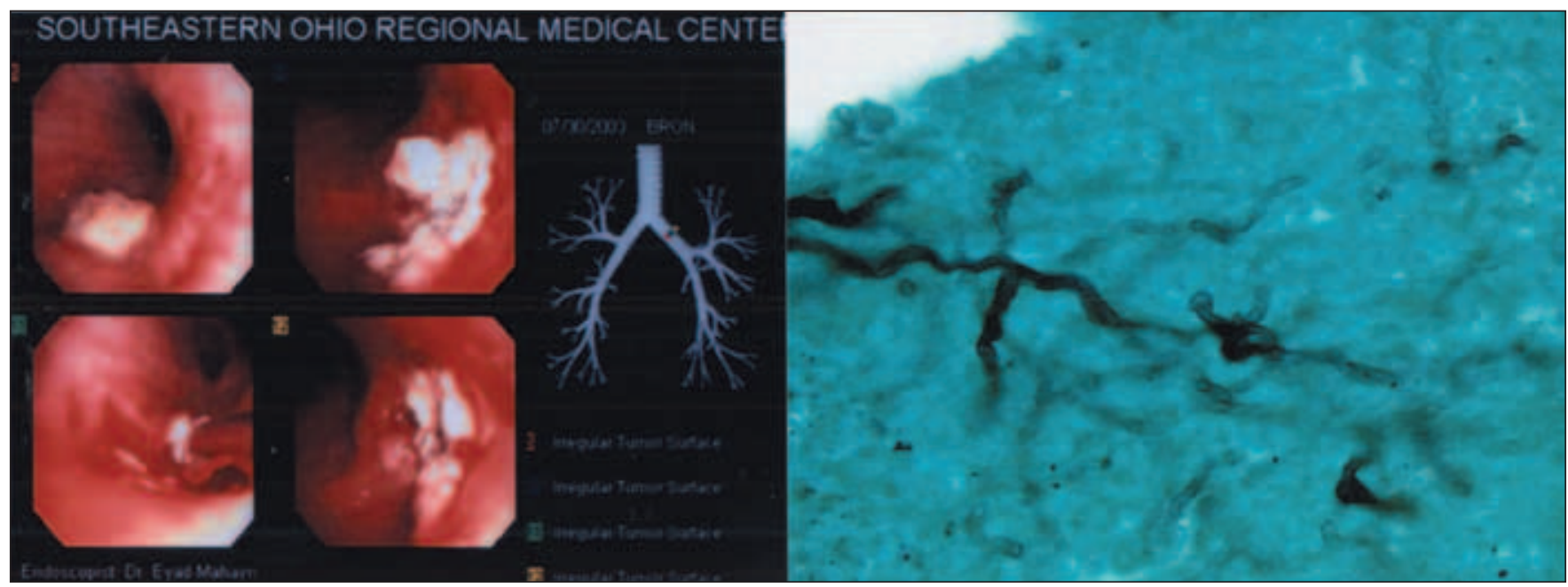

Figure 2) Infection group. A striking verrucous fungating mass on the medial wall of the left mainstem at the cartilaginous membranous junction was observed (left). Histological examination, along with cultures, confirmed the diagnosis of Malbranchea (Table 1, patient 5). Pleomorphic hyphal fungal elements are seen ( right) (Grocott methenamine silver stain, original magnification $\times 1000$ )

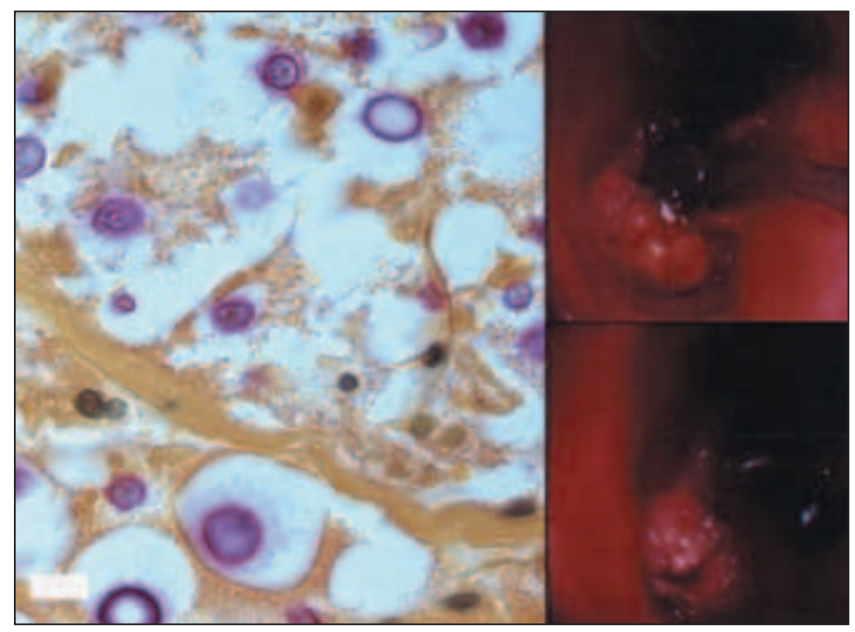

Figure 3) A polypoid mass obstructs the proximal left mainstem bronchus. Light microscopic assessment revealed yeast forms with a prominent mucicarmine-positive capsule consistent with Cryptococcus (mucicarmine stain, original magnification $\times 1000$ ) $($ Table 1, patient 1)

\section{Endobronchial fungal disease (five cases)}

There were four women and one man who ranged in age from 32 to 82 years. In four patients, the presenting symptom was hemoptysis. The symptom duration ranged from 10 days to several months. All patients had evidence of obstruction; the lesions were in the right upper lobe $(\mathrm{n}=1)$, right middle lobe $(\mathrm{n}=1)$, left lower lobe $(\mathrm{n}=1)$ and left mainstem $(\mathrm{n}=2)$ (Figure 2). Three patients were resected with lobectomy for control of hemoptysis. One patient underwent PDT to relieve their obstructive symptoms. Culture and histological evaluation confirmed the presence of Histoplasma capsulatum (3), Cryptococcus neoformans (Figure 3) (1) and Malbranchea species (1). A patient with histoplasmosis developed a tracheoesophageal fistula after bronchoplasty and resection of the broncholith. This was successfully controlled with primary repair and an intercostal muscle flap.

\section{Primary bronchogenic malignant melanoma (one case)}

The patient was an asymptomatic 77-year-old woman who presented with an abnormal $\mathrm{x}$-ray bronchoscopic examination

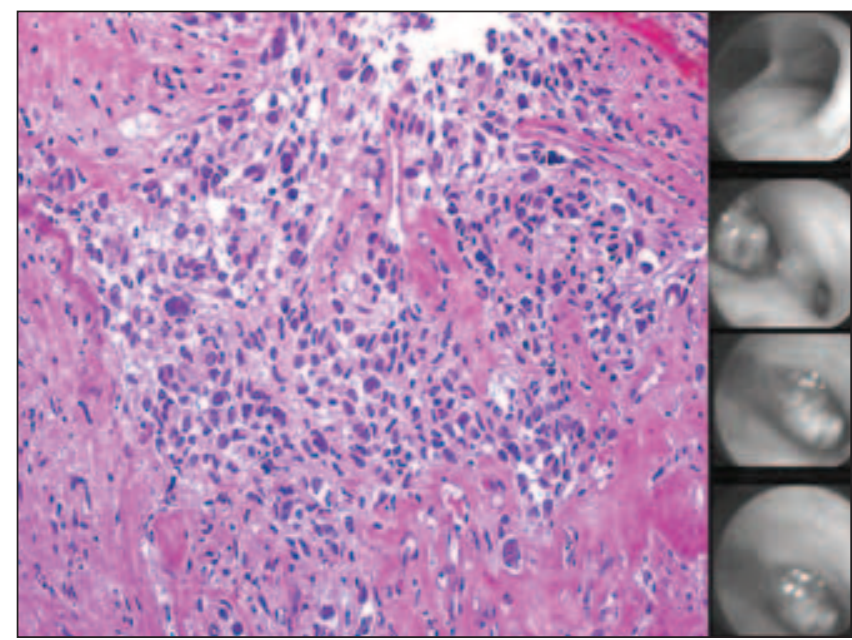

Figure 4) Primary bronchogenic melanoma. An endoluminal mass obstructs the right middle lobe orifice. Histological examination confirmed the diagnosis of primary bronchogenic melanoma (Table 1, patient 6) (Hematoxylin and eosin stain, original magnification $\times 200$ )

that revealed an obstructing lesion of the bronchus intermedius. A computed tomography scan showed a right lower lobe mass and liver metastasis. Bronchoscopic biopsy established a diagnosis of primary endobronchial malignant melanoma (Figure 4). Immunohistochemical stains confirmed the diagnosis, with the tumour cells positive for the melanocyte markers MART-1, Melan-A, HMB-45 and S-100.

\section{Hodgkin's lymphoma (three cases)}

In all cases, there was extensive mediastinal disease with secondary extension into the bronchus. In two of the cases, the endobronchial symptoms defined the initial presentation of the disease, while one patient had a history of Hodgkin's lymphoma.

One patient developed severe obstructive symptoms due to extensive right mainstem involvement. The biopsy was initially interpreted as representing small cell carcinoma. PDT was administered, and patency of the mainstem was established. Additional pathological evaluation documented Hodgkin's lymphoma. The patient is now in remission following radiotherapy and chemotherapy. 


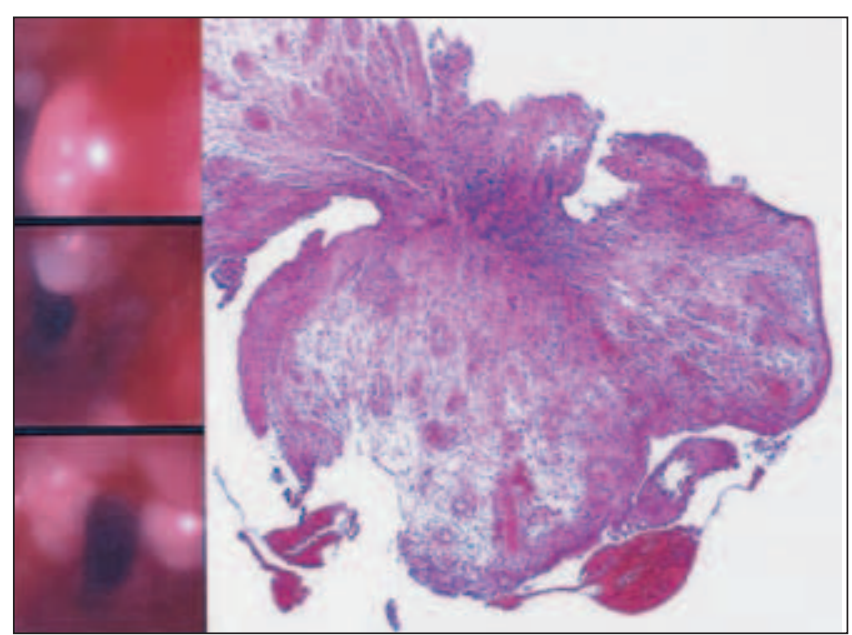

Figure 5) Pseudopolyp. There was a polypoid glistening mass in the proximal trachea on bronchoscopy. Light microscopic assessment revealed polypoid granulation tissue response with neovascularization and edema (Table 1, patient 13) (Hematoxylin and eosin stain, original magnification $\times 40$ )

The second patient with Hodgkin's lymphoma was a 60-year-old man with a history of chronic cough and weight loss. A computed tomography scan revealed extensive mediastinal and hilar lymphadenopathy with partial compression of the superior vena cava by a paratracheal lymph node. Bronchoscopic assessment revealed a pedunculated lesion obstructing the right main stem bronchus.

The third patient with Hodgkin's lymphoma presented with obstructive symptoms six months after his initial diagnosis. Bronchoscopic examination revealed $75 \%$ obstruction of the right lower lobe bronchus. At the level of the origin of the bronchus intermedius, the entire membranous portion of the bronchial wall was necrotic and absent, communicating with the mediastinum and esophagus.

\section{Endobronchial lipoma (one case)}

A 42-year-old man presented with progressive cough. He was taken to the operating room for bronchoscopy with endobronchial biopsy due to persistent symptoms. The patient was found to have an endobronchial obstruction in the middle lobe extending into the mainstem bronchus. He underwent right middle and lower bilobectomy. The microscopic examination revealed an endobronchial lipoma.

\section{Broncholith (one case)}

The patient had a foreign body in the airway that became affixed to the bronchial wall. In the left lower lobe bronchus, there was $90 \%$ obstruction by cheesy white material. Using a bronchial protected brush catheter, a foreign body was retrieved from the posterior lower lobe basal segment.

\section{Inflammatory pseudopolyps (one case)}

The patient presented with cough and wheezing. In the trachea, there was $50 \%$ obstruction by a polypoid mass (Figure 5). A biopsy was compatible with an inflammatory pseudopolyp; the presumed etiology was recurrent aspiration.

\section{DISCUSSION}

We have presented 25 cases of patients with endobronchial lesions in which the clinical presentation mimicked primary bronchogenic carcinoma. The cases could be broadly categorized, according to their etiology, into metastatic tumours, infection, lymphoma, primary bronchogenic melanoma, submucosal lipoma, broncholiths and inflammatory pseudopolyps.

Metastatic lesions represented the largest group and included adenocarcinomas of breast, kidney and colonic origin, and squamous cell carcinoma of the larynx and piriform sinus, developing within 1.5 to 4.6 years from the initial tumour resection. Most patients had intraparenchymal and extrapulmonary metastatic disease at the time of the endobronchial presentation of their disease, presaging the endobronchial disease by a mean of 1.8 years. As in other series $(1,4)$, upper lobes and bronchus intermedius were preferentially involved. The most frequently reported metastatic endobronchial tumours are those of thyroid, head/neck and breast origin, with median and mean survival times of nine months and 15.5 months, respectively $(1,4)$. One of the great diagnostic conundrums, of course, is the distinction of primary bronchogenic adenocarcinoma from metastatic adenocarcinoma. Immunohistochemistry is a critical diagnostic adjunct in this regard. First, there are very specific markers indicative of primary bronchogenic carcinoma including thyroid transcription factor-1 and apoprotein-A1. The CK profile can also be useful. Most adenocarcinomas of gastrointestinal tract origin are CK 20-positive and CK 7-negative, while primary bronchogenic tumours exhibit a converse profile, being CK 7-positive and CK 20-negative (7-9).

One patient in our case series presented with primary bronchogenic malignant melanoma. This diagnosis was established only after careful exclusion of primary cutaneous malignant melanoma (10). The lesions typically present as central endobronchial lesions. Immunohistochemistry may be critical for establishing a diagnosis because there are very specific melanocyte markers including HMB-45, S-100, Melan-A, and MART-1. In one series (10), five patients died of metastatic disease four to 32 months after resection (median 14 months).

In the current series, the only encountered form of endobronchial lymphoma was Hodgkin's disease, which defined the initial presentation of the disease in two patients. In all our cases, the endobronchial nature of the disease reflected contiguous spread from adjacent lymph nodes. In our recent review (5), the average age of presentation in these patients was 42.3 years (range 18 to 83 years), there was a slight preponderance of males, and cough was the most frequent sign. The lesions were typically polypoid, and there appeared to be a predilection for involvement of the right bronchial tree relative to the left bronchus (5).

An endobronchial lipoma of the left main stem bronchus was found in one of the patients. The origin of endobronchial lipoma is adipose cells of the peribronchial and, occasionally, submucosal tissues of the large bronchi (6). These tumours are most often seen in men in the sixth decade of life, especially in those with obesity, and the tumours are typically located in mainstem bronchi and exhibit a pedunculated morphology (6).

All cases of infection-based endobronchial disease were fungal in nature. One patient in whom the infection was attributable to $\mathrm{C}$ neoformans had AIDS, while the other patients were immunocompetent. There are prior reports (2), mainly in immunocompetent patients, in which an initial endobronchial presentation of cryptococcosis was observed. Three of our cases represented histoplasmosis with endobronchial involvement, specifically of the right upper lobe and right middle lobes. Usually, endobronchial presentations of histoplasmosis reflect the penetration of a calcified lymph node through the bronchial wall, causing an erosive inflammatory endobronchial lesion. The predilection for fungal disease to 
involve the bronchus intermedius likely reflects the high concentration of lymph nodes in the area (3). Surprisingly, in one patient, the isolated pathogen was a Malbranchea speices. Malbranchea is a type of dermatophyte which requires keratin for growth and, hence, infection is usually restricted to hair, nails and superficial skin. However, there have been no reports of this particular fungus causing disease in humans (11).

One patient in our series had broncholithiasis secondary to a foreign body. Broncholithiasis is defined as a condition in which calcified or ossified material is present within the bronchial lumen (12). The most common cause of broncholithiasis is erosion by a calcified lymph node into the bronchial lumen, usually in the context of tuberculosis or histoplasmosis. An inflammatory polyp related to repeated episodes of aspiration defined another cause of endobronchial obstruction. A variety of chronic inflammatory insults could lead to the development of this distinctive non-neoplastic endobronchial lesion (13).

\section{CONCLUSIONS}

Endobronchial mimics of primary bronchogenic malignancy comprise an interesting spectrum of lesions with diverse causes, with over one-half of these lesions representing endobronchial metastatic disease primarily from extrapulmonary

\section{REFERENCES}

1. Salud A, Porcel JM, Rovirosa A, Bellmunt J. Endobronchial metastatic disease: Analysis of 32 cases. J Surg Oncol 1996;62:249-52.

2. Mahida P, Morar R, Goolam Mahomed A, Song E, Tissandie JP, Feldman C. Cryptococcosis: An unusual cause of endobronchial obstruction. Eur Respir J 1996;9:837-9.

3. Ross P Jr, Magro CM, King MA. Endobronchial histoplasmosis: A masquerade of primary endobronchial neoplasia - a clinical study of four cases. Ann Thorac Surg 2004;78:277-81.

4. Shepherd MP. Endobronchial metastatic disease. Thorax 1982;37:362-5.

5. Kiani B, Magro CM, Ross P. Endobronchial presentation of Hodgkin lymphoma: A review of the literature. Ann Thorac Surg 2003;76:967-72.

6. Farsad GR, Makoui C. Endobronchial lipoma. Am Surg 1981;47:236-8.

7. Srodon M, Westra WH. Immunohistochemical staining for thyroid transcription factor-1: A helpful aid in discerning primary site of tumor origin in patients with brain metastases. Hum Pathol 2002;33:642-5. adenocarcinomas. The critical role of the biopsy in establishing a definitive diagnosis is self-evident; however, the present study and other studies suggest that certain aspects of the prebiopsy assessment could lead one to suspect a diagnosis other than primary bronchogenic carcinoma. Perhaps the most obvious of these clues would be those encountered in the context of metastatic endobronchial disease. Typically, these patients had an established history of extrapulmonary malignancy, representing, in most cases, adenocarcinomas of extrapulmonary derivation. Hence, eliciting a positive history of primary extrapulmonary malignancy, especially when associated with upper lobe involvement, should lead one to consider this diagnostic possibility. Patients who are younger (younger than 45 years of age) with apparent mediastinal disease could have endobronchial disease on the basis of lymph node disease, be it in the context of lymphoma or infectionbased lymphadenitis, especially when there is involvement of the bronchus intermedius.

ACKNOWLEDGEMENT: The authors wish to thank Aimee Sisinger for her excellent editorial assistance. We would like to thank Dr James N Allen from The Ohio State University (Columbus, Ohio) for providing clinical information and images on two of the cases.

8. Kummar S, Fogarasi M, Canova A, Mota A, Ciesielski T. Cytokeratin 7 and 20 staining for the diagnosis of lung and colorectal adenocarcinoma. Br J Cancer 2002;86:1884-7.

9. Goldmann T, Galle J, Wiedorn KH, et al. Diagnostic value of immunohistochemically detected surfactant - apoprotein-A in malignant tumors located in the lungs: Report of two cases. Ann Diagn Pathol 2001;5:84-90.

10. Wilson RW, Moran CA. Primary melanoma of the lung: A clinicopathologic and immunohistochemical study of eight cases. Am J Surg Pathol 1997;21:1196-202.

11. Filipello Marchisio V. Keratinolytic and keratinophilic fungi of children's sandpits in the city of Turin. Mycopathologia 1986;94:163-72.

12. Seo JB, Song KS, Lee JS, et al. Broncholithiasis: Review of the causes with radiologic-pathologic correlation. Radiographics 2002;22:S199-213.

13. McShane D, Nicholson AG, Goldstraw P, et al. Inflammatory endobronchial polyps in childhood: Clinical spectrum and possible link to mechanical ventilation. Pediatr Pulmonol 2002;34:79-84. 


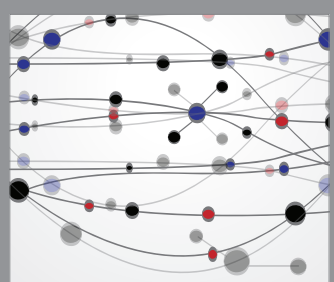

The Scientific World Journal
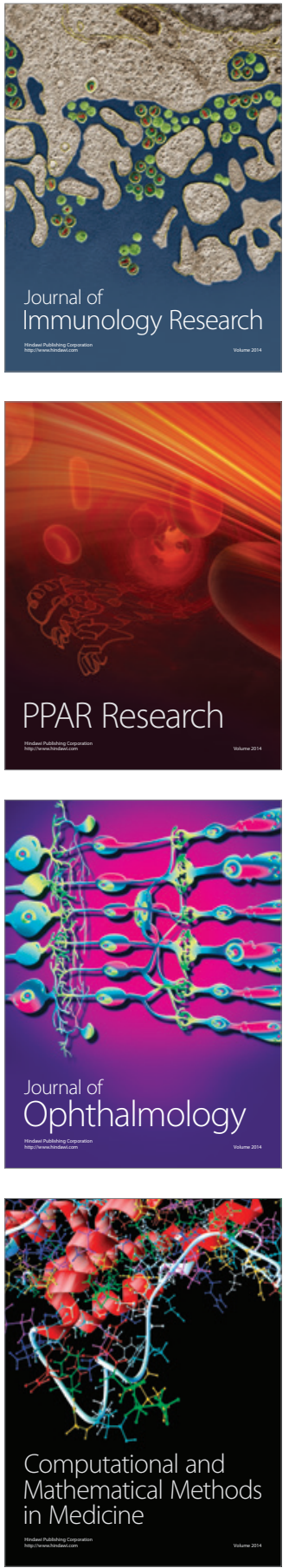

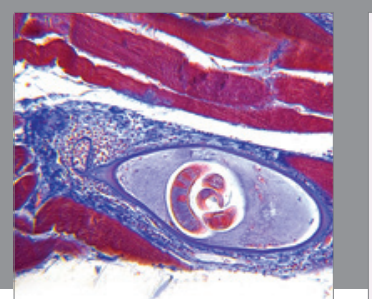

Gastroenterology Research and Practice

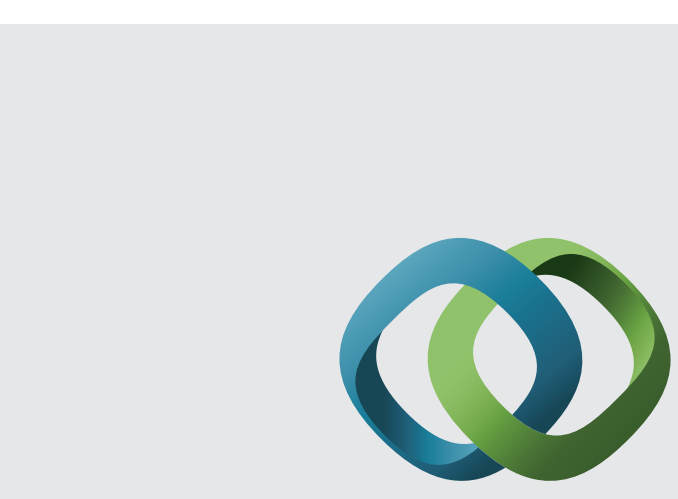

\section{Hindawi}

Submit your manuscripts at

http://www.hindawi.com
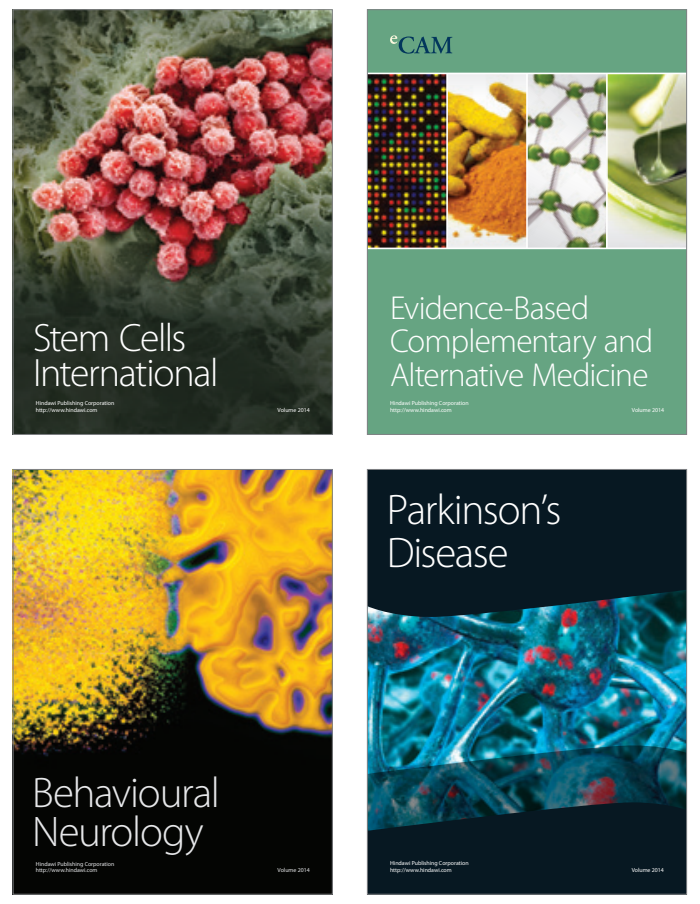
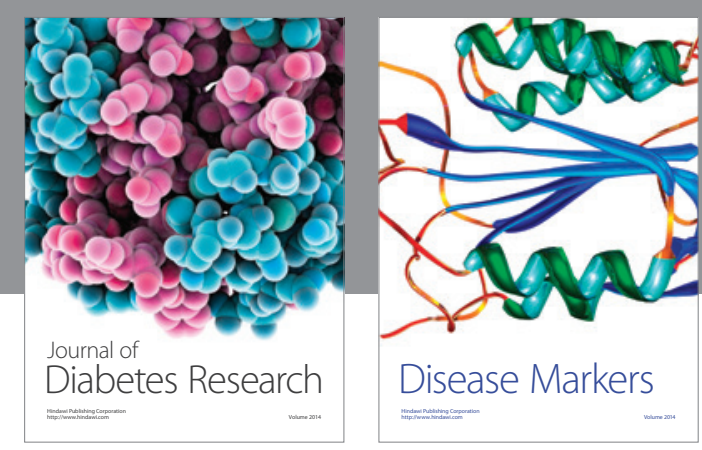

Disease Markers
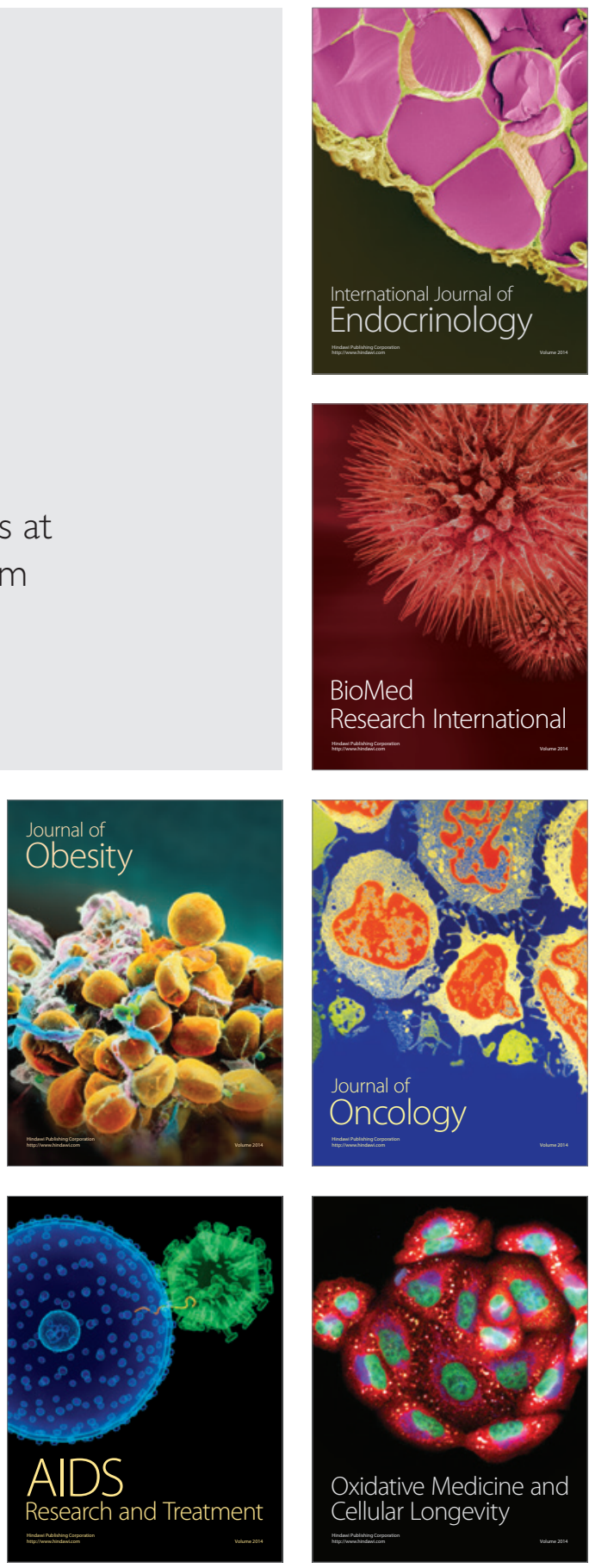